Original Article

\title{
EVALUATION OF BACTERICIDAL ACTIVITY OF AN ANTISEPTIC GELTHROUGH THE DILUTION-NEUTRALIZATION METHOD
}

\section{JANETH DEL CARMEN ARIAS PALACIOS ${ }^{1}$, LIBARDO HERNANDEZ ESQUIVEL ${ }^{2}$, DORELLY SANDOVAL MEDINA ${ }^{3}$, TATIANA DIAZ B. ${ }^{3}$}

\author{
1Bacteriologist. M. Sc. Grupo Biotecnologia Ambiental e Industrial Departmento de Microbiología. Facultad de Ciencias. Pontificia \\ Universidad Javeriana, Bogota, Colombia, ${ }^{2}$ Pharmaceutical Chemist Scientific Manager-Vicar ${ }^{\circledR}$ Bogota, Colombia, ${ }^{3}$ Industrial \\ Microbiologist-Pontificia Universidad Javeriana Bogota, Colombia \\ Email: jdcarias@javeriana.edu.co
}

Received: 06 Mar 2018 Revised and Accepted: 20 Dec 2018

\begin{abstract}
Objective: To evaluate the bactericidal activity of an antiseptic gel for hygiene and disinfection of the hands by rubbing.

Methods: The dilution-neutralization method was used according to Colombian Technical Standard NTC, 2009, 12, 16 in Instituto Colombiano de Normas Técnicas y Certificación (ICONTEC), 5 strains, over 6 different types and with 6 replicas per time were exposed to the antiseptic gel, using Letheen Broth as a neutralizer substance.

Results: A 99\% of reduction was obtained with Staphylococcus aureus 6538, Enterococos hirae 10541, Pseudomonas aeruginosa 15442 and Klebsiella sp, within the first $30 \mathrm{~s}$ of exposure to the gel and within the first $60 \mathrm{~s}$ of exposure using the Escherichia coli 19538. All strains used coming from American Type Culture Collection (ATCC).
\end{abstract}

Conclusion: It was confirmed that the product is effective. In presence of a neutralizer substance, the microorganisms were not inhibit, so the growing reduction occurs due to the action of the product.

Keywords: Bactericidal activity, Antiseptic gel, Dilution-neutralization, Clean hands

(C) 2019 The Authors. Published by Innovare Academic Sciences Pvt Ltd. This is an open access article under the CC BY license (http://creativecommons.org/licenses/by/4.0/] DOI: http://dx.doi.org/10.22159/ijpps.2019v11i2.25716

\section{INTRODUCTION}

Most of the infections present in hospitals and medical facilities are linked with poor hygiene practices at the moment of patience assistance, this is known to be a public health issue. The right sanitization of the health care personnel's hands is considered an issue of vital importance to prevent and control infections [1]

It becomes necessary to use effective products to counter the propagation of infectious microorganisms and diminish the risk of contracting diseases, some of the products that are used in the medical facilities are antiseptic rubs, these leave-on products are highly recommended after a plain soap and water hand wash, because most of the time the soap does not have the antibacterial biocidal properties to destroy or to inhibit the development of the targeted microorganisms that can be present on living tissue [2, 3].

The main objective of this work was to evaluate, experimentally, the bactericidal activity of an antiseptic gel based on $70 \%$ ethanol (clean hands $₫$ Vicar Pharmaceutics) for hygiene and disinfection of the hands by rubbing. Experiments with five different strains of microorganisms and different times of exposures to the gel were made to determine the effectiveness of the antiseptic according to the Colombian Technical Standard NTC, 2009, 12, 16 ICONTEC. The technique used during the process was the dilution-neutralization technique $[4,5]$.

\section{MATERIALS AND METHODS}

The test was performed using Icontec International, 2008, NTC, 200912-16 ICONTEC, Disinfectants, and chemical antiseptics. Quantitative suspension test for the evaluation of the bactericidal activity of products for the treatment by rubbing and hygienic and surgical washing of the hands. Test method and requirement (Phase 2, stage 1).

The principle of the test is based on the minimum bactericidal concentration (mbc) tested capable of reduce in five logarithmic units $(5 \log 10)$ a suspension of bacteria in $5 \mathrm{~min}$ of contact with the disinfectant at $20^{\circ} \mathrm{C}$. Is establishes whether a chemical disinfectant that forms a homogeneous preparation physically stable when diluted and in water has a bactericide activity, for these, there is a specific neutralizer [6].

This method starts with preparation of the bacterial suspension for test and validation, from a bacterial suspension where values are giving in a number of colonies forming units (cfu), of $1.5 \times 10^{8} \mathrm{cfu} . \mathrm{ml}^{-1}$ and $5.0 \times 10^{8} \mathrm{cfu} . \mathrm{ml}^{-1}$ should be adjusted whit a diluent (ICONTEC, 2007). The count is carried out by the preparation of serial dilutions, from these the $10^{-6}$ and $10^{-7}$ dilutions using plate sowing technique.

For the test with the neutralizer, the disinfectant was reacted with a bacterial suspension under normal conditions, the reaction was stopped with the neutralizing substance [7]

Neutralizers action was tested to verify non-toxicity or interference of the neutralizer, by mixing the disinfectant for $10 \mathrm{~min}$ at $20^{\circ} \mathrm{C}$, then mixed and added a bacterial suspension, where after $5 \mathrm{~min}$, the sample is mixed, and the count is carried out by plating in duplicate where the counting of the samples is carried out and determine the number of colony forming units (cfu), and this is compared with the initial inoculum. There should not be a $50 \%$ reduction in the number of bacteria compared to the initial inoculum.

The product used for the evaluation was an antiseptic gel based on $70 \%$ ethanol (clean hands®), produced by Vicar Pharmaceutics. An $80 \%$ concentration of the commercial product was used for the test.

The test strains were provided by microorganism collections of the Pontificia Universidad Javeriana: Pseudomonas aeruginosa 15442, Staphylococcus aureus 6538, Enterococcus hirae 1054, Escherichia coli 10538 and Klebsiella sp. The exposure times were in min: 0, 0.25 $\min (15 \mathrm{~s}), 0.5 \mathrm{~min}(30 \mathrm{~s}), 1 \mathrm{~min}(60 \mathrm{~s}), 2 \mathrm{~min}(120 \mathrm{~s})$ and $4 \min (240$ s) with six replicas per time of exposure. The time 0 corresponding to the initial count.

\section{RESULTS}

The preparation of every suspension of microorganisms started with suspensions that were closed to the McFarland Standard No. 1, with 0.199 absorbance. Then, after the preparation of a number of 
suspensions with different cell densities, the chosen suspension for Staphylococcus aureus 6538 was of 0.186 absorbances and an obtained count of $4,0 \times 10^{8} \mathrm{cfu} . \mathrm{ml}^{-1}$ that meets the requirement of the norm; this value was considered for the $S$. aureus during the different tests. With Pseudomonas aeruginosa 15442 the chosen suspension was of 0.184 absorbances and an obtained count of 2.7 $\mathrm{x} 10^{8} \mathrm{cfu} . \mathrm{ml}^{-1}$. A similar process was followed for every strain, the chosen suspension for each strain is summarized in table 1 [8].

Table 1: Concentrations of validation and test suspensions

\begin{tabular}{lll}
\hline Microorganism & Test suspension (N) cfu. $\mathbf{~ m l}^{-1}$ & ${\text { Validation suspension (Nv)cfu. } \mathbf{~ m l}^{-1}}^{\mathbf{1}}$ \\
\hline Staphylococcus aureus & $4.0 \times 10^{8}$ & $6.9 \times 10^{2}$ \\
Pseudomonas aeruginosa & $2.7 \times 10^{8}$ & $6.1 \times 10^{2}$ \\
Enterococcus hirae & $2.1 \times 10^{8}$ & $4.8 \times 10^{2}$ \\
Klebsiella sp. & $3.1 \times 10^{8}$ & $7.1 \times 10^{2}$ \\
Escherichia coli & $4.6 \times 10^{8}$ & $1.1 \times 10^{3}$ \\
\hline
\end{tabular}

Once the absorbance values for each microorganism were set according to table 1 , the validation suspension was set with a cell density between 4.5 $\mathrm{x} 10^{2} \mathrm{cfu} \cdot \mathrm{ml}^{-1}$ and $3 \times 10^{3} \mathrm{cfu} \cdot \mathrm{ml}^{-1}$.

To do that, it was necessary to make some dilutions and tests to obtain a concentration that was inside the theoretical limits. An additional dilution was prepared to confirm that the determined cell density was inside the limits, the same process was repeated for every test strain, to obtain the different validation suspensions, the validation suspension for each strain is also summarized in table 1.

\section{B-Parameter control of the non-toxicity of the neutralizer}

Considering that the neutralizer was used to stop the bactericidal action after the contact between the antiseptic and the microorganism, this parameter determines the absence of toxicity of the neutralizer against any of the microorganisms used in the dilution-neutralization technique. The chosen neutralizer was the
Letheen broth because of its effectiveness in the neutralization of most of the antiseptics, due to the presence of soy lecithin, which in addition to providing nutrients to the culture medium, acts as an emulsifying agent; In the same way, the combination of lecithin with Tween, allows to neutralize the ethyl alcohol that is the active principle of the evaluated product [3-9].

According to the results in table 2, growth of the microorganisms in the presence of the neutralizer with a concentration equivalent to the one in the validation suspension was evidenced. These results indicate that the Letheen broth, did not affect the development of the microorganisms, likewise did not affect the evaluation of the bactericidal test and therefore the results obtained in the evaluation of the antiseptic are reliable, confirming that the neutralizer was not a cause of inhibition of microorganisms.

Table 2: B-Parameter control of the toxicity of the neutralizer (cfu. ml-1)

\begin{tabular}{lll}
\hline Microorganism & B Control (cfu. ml-1) & B Control count (cfu. ml-1) \\
\hline Staphylococcus aureus & & $7.5 \times 10^{2}$ \\
Pseudomonas aeruginosa & 63.87 & $6.3 \times 10^{2}$ \\
Enterococcus hirae & 52.82 & $5.2 \times 10^{2}$ \\
Klebsiella sp. & 73.26 & $7.3 \times 10^{2}$ \\
Escherichia coli & 119.79 & $1.2 \times 10^{3}$ \\
\hline
\end{tabular}

\section{C-Parameter control of the dilution-neutralization method (cfu.} $\mathbf{m l}^{-1}$ )

To verify the effectiveness of the neutralizer after five min of contact with the gel, the microorganism was inoculated after neutralizing the product, to observe that the alcohol in neutralized gel does not cause an inhibitory effect on it. Table 3 shows that the microorganisms showed a wide development, which suggests that the neutralizer was effective, indicating that the product acts on the microorganism only until it is neutralized, guaranteeing that the counts reported in the evaluation of the antiseptic in the different contact times are reliable.

Although the neutralizer was effective on the product, there was a gradual decrease in the concentration at each time. This shows that although it stops its bactericidal effect it reaches to slightly inhibit the microorganisms; however, it was considered that this does not affect the bactericidal test since the test suspension has an initial inoculum of very high concentration and if there was any decrease at the time of performing the bactericidal test, it would not be appreciable.

Table 3: C-parameter control of the dilution-neutralization method (cfu. $\mathrm{ml}^{-1}$ )

\begin{tabular}{llllll}
\hline Microorganism & \multicolumn{2}{l}{ Contact time (min) } & & $\mathbf{0}$ \\
\cline { 2 - 5 } & $\mathbf{0}$ & $\mathbf{0 . 2 5}$ & $\mathbf{0 . 5}$ & $\mathbf{1}$ \\
\hline Staphylococcus aureus & 80.61 & 79.60 & 77.95 & 77.14 & 71.42 \\
Pseudomonas aeruginosa & 70.20 & 69.38 & 68.77 & 65.30 & 62.24 \\
Enterococcus hirae & 56.12 & 55.10 & 53.67 & 53.87 & 48.40 \\
Klebsiella sp. & 82.65 & 82.04 & 81.43 & 80.40 & 77.75 \\
Escherichia coli & 121.02 & 120.20 & 118.77 & 120.20 \\
\hline
\end{tabular}

\section{Bactericidal activity determination of the product}

In this test, the analyzed antiseptic was exposed during six different times of contact with each of the test microorganisms, neutralizing the bactericidal reaction with Letheen broth at times $0,0.25,0.5,1,2$ and $4 \mathrm{~min}$. A wide reduction was observed at $0.5 \mathrm{~min}$ of contact with the gel in all cases, except for Escherichia coli, where the reduction at the minute of contact was evidenced as shown in table 4 and mortality percentage of each micro-organisms in the presence of gel in evaluation, was shown in table 5. 
Table 4: Bactericidal activity determination of the product (cfu. ml-1)

\begin{tabular}{|c|c|c|c|c|c|c|}
\hline \multirow[t]{2}{*}{ Microorganism } & \multicolumn{6}{|c|}{ Contact time (min) } \\
\hline & $\mathbf{0}$ & 0.25 & 0.5 & 1 & 2 & 4 \\
\hline Staphylococcus aureus & $>3 \times 10^{2}$ & $>3 \times 10^{2}$ & 180.6 & 64.5 & 7.3 & $<1.5 \times 10^{2}$ \\
\hline Pseudomonas aeruginosa & $>3 \times 10^{2}$ & $>3 \times 10^{2}$ & 232.04 & 102.24 & 10.81 & $<1.5 \times 10^{2}$ \\
\hline Enterococcus hirae & $>3 \times 10^{2}$ & $>3 \times 10^{2}$ & 173.8 & 77.14 & 10.2 & $<1.5 \times 10^{2}$ \\
\hline Klebsiella sp. & $>3 \times 10^{2}$ & $>3 \times 10^{2}$ & 194.7 & 143.26 & 16.12 & $<1.5 \times 10^{2}$ \\
\hline Escherichia coli & $>3 \times 10^{2}$ & $>3 \times 10^{2}$ & $>3 \times 10^{2}$ & 131.02 & 40.43 & $<1.5 \times 10^{2}$ \\
\hline
\end{tabular}

Table 5: Mortality percentage of test microorganisms in the presence of the gel in evaluation

\begin{tabular}{llllll}
\hline Microorganism & \multicolumn{2}{l}{ Contact time (min) } & & \\
\cline { 2 - 6 } & $\mathbf{0}$ & $\mathbf{0 . 2 5}$ & $\mathbf{0 . 5}$ & $\mathbf{1}$ & $\mathbf{2}$ \\
\hline Staphylococcus aureus & $0 \%$ & $0 \%$ & $99.90 \%$ & $99.90 \%$ & $99.90 \%$ \\
Pseudomonas aeruginosa & $0 \%$ & $0 \%$ & $99.90 \%$ & $99.90 \%$ & $99.90 \%$ \\
Enterococcus hirae & $0 \%$ & $0 \%$ & $99.90 \%$ & $99.90 \%$ & $99.90 \%$ \\
Klebsiella sp & $0 \%$ & $0 \%$ & $99.90 \%$ & $99.90 \%$ & $99 \%$ \\
Escherichia coli & $0 \%$ & $0 \%$ & $0 \%$ & $99.90 \%$ & $99.90 \%$ \\
\hline
\end{tabular}

Evaluates the effectiveness of the product, confirms that the product exerts a bactericidal action on microorganisms tested. In this case, the product evaluated was a gel based on ethyl alcohol for cleaning and disinfection of hands, given the importance of the use of these products, especially in the medical-surgical field where is important to take care of nosocomial infections transmission $[9,11]$.

The study to reduce the hands' microbial load becomes important after the publication of the CDC on the hygiene of the hands, for this reason it becomes indispensable the evaluation of the bactericidal activity of each product used for this purpose, under rigorous test conditions, as in this case ethanol-based gel, against high concentrations of most common microorganisms in nosocomial infections $[10,11]$.

A reduction of $10^{5}$ counts was expected at least at 1 min of exposure times, as suggested by the standard. This test exceeded the expected, achieving the reduction for the first four microorganisms in a time of $30 \mathrm{~s}$, thus giving good results since for many products used in hand rubs an exposure time of $30 \mathrm{~s}$ is recommended [12].

\section{DISCUSSION}

Recent results obtained by $[2,10]$, show that with some antiseptics for hand hygiene the same efficacy can be achieved in a shorter time of use, such as $15 \mathrm{~s}$; they evaluated the bactericidal activity of a gel based on ethanol, demonstrating the reduction in $15 \mathrm{~s}$ with some of the most common nosocomial pathogens such as Sthapylococcus aureus and Pseudomonas aeruginosa, using TSA agar plates (Trypticase soy) as was done in the present work. It was possible to overcome what was expected, demonstrating that the antiseptic evaluated was effective against the microorganisms evaluated, thus fulfilling the parameters of the standard [13].

On the other hand, Gram-positive microorganisms present a greater sensibility to the product compared to the Gram-negative microorganisms such as Escherichia coli, with which a count greater than $300 \mathrm{cfu}$. $\mathrm{ml}^{-1}$ was obtained at $30 \mathrm{~s}$, therefore the specification of the standard was considered and the result was reported as $>3 \times 10^{2}$.

Some authors, [14-16] assure that the strains that present greater resistance in vitro to antimicrobial products are Escherichia coli and Klebsiella sp. However, considering the initial concentration of the inoculum of work for E. coli, a reduction of $99.9 \%$ was demonstrated for Escherichia coli from one minute of contact, results that are shown in table 5.

Although Klebsiella sp and Pseudomonas aeruginosa had a high reduction, the counts were also higher than those of Enterococcus hirae and Staphylococcus aureus at $30 \mathrm{~s}$ and at one minute of contact. This was not an issue at the moment of finding the percentage of mortality, considering that the difference in the count was not considerable. In a similar way, the reduction was high with respect to the initial inoculum of each one, resulting in a $99.9 \%$ elimination of the microorganisms in $30 \mathrm{~s}$ of exposure to the gel evaluated unlike Escherichia coli, which achieved this reduction at one minute of contact.

After 4 min of exposition to gel, the results for every microorganism were very similar, although a growth was present, the number of colonies in every one of the 6 replicas was smaller than 15, that is why, according to the standard, the result was reported as smaller than 150 (table 4). A reduction of $0 \%$ was considered for every count smaller than $>3 \times 10^{2}$.

The evaluation of the bactericidal activity of the gel, showed that this can generate a logarithmic reduction greater than 5 , and that it is effective at the minute of contact with all the microorganisms tested, therefore, it can be said that this product is effective as a bactericidal preparation for disinfection and hygiene of hands. This suggests that the gel efficiency can be performed under practical conditions on the hands. In this way, it can be an important mechanism for disinfection in the medical facilities in order to prevent the transmission of infectious diseases.

\section{CONCLUSION}

The in vitro bactericidal activity of the $70 \%$ alcohol-based antiseptic gel (clean hands $®$ ), developed to use by friction in hygiene and disinfection of hands, was evaluated, demonstrating the antiseptic effect under the conditions of the study.

It can be stated that the product shows a reduction of $10^{5}$ in the count of viable microorganisms, in a period of $1 \mathrm{~min} .+/-5 \mathrm{~s}$ at $20^{\circ} \mathrm{C}$ and under the conditions defined by this test when the test organisms are Staphylococcus aureus, Pseudomonas aeruginosa, Enterococcus hirae, Escherichia coli, and Klebsiellsa sp. This product can be used as bactericidal in the hands' sanitization process, but it is suggested to make an evaluation process to test its efficiency in conditions that simulate the practical conditions of the hand. It was verified that the used neutralizer did not interfere in the obtained results during the bactericidal test, since it did not cause any considerable inhibitions in the control (B-Parameter). The effectiveness of the dilution-neutralization (C-parameter) method was also verified, assuring that the test results are reliable and that the method is applicable in the evaluation in this type of antiseptics.

\section{AUTHORS CONTRIBUTIONS}

All authors had equally contributed the research work

\section{CONFLICTS OF INTERESTS}

All authors have none to declare

\section{REFERENCES}

1. WHO. World Health Organization. Guidelines on hand hygiene in health care: first global patient safety challenge clean care is safer care. World Health; 2009. 
2. Ochwoto M, Muita L, Talaam K, Wanjala C, Ogeto F, Wachira F et al. Anti-bacterial efficacy of alcoholic hand rubs in the Kenyan market, 2015. Antimicrob Resist Infect Control 2017;6:1-17.

3. Best EL, Parnell P, Wilcox MH. The potential of alcohol release doorplates to reduce surface contamination during hand contact. J Hosp Infect 2017;97:427-9.

4. ICONTEC NTC Disinfectants and antiseptic chemicals Quantitative assay of suspension for the evaluation of the bactericidal activity of products for the treatment and hygienic and surgical washing of the hands. Testing Method Icontec International; 2009.

5. Enwa F, Anie C, Oghenejobo M, Ilaya A. Evaluation of the comparative activity of alcohol-based hand sanitizers and toilet soaps against some bacterial isolates. GJSFR: C Biol Sci 2015; 15:3.

6. Wirtanen G. Microbiological methods for testing disinfectant efficiency on Pseudomonas biofilm. Colloids Surf B 2001;20:37-50.

7. Alvarez A, Espigares E, Galvez R. Evaluation of disinfectants Dilution-neutralization method. Hig San Amb 2001;1:1-5.

8. Espigares E, Bueno A, Fernandez M, Espigares M. Efficacy of some neutralizers in suspension tests determining the activity of disinfectants. J Hosp Infect 2003;55:137-40.

9. Bermejo I, Wertz A, Bencomo B, Lesnaberes P, Notario R. Effect of alcohol-gel hand hygiene on nosocomial infections due to multi-resistant Klebsiella pneumoniae. Medicina (B. Aires) 2003;63:715-20

10. Kampf G, Hollingsworth A. Comprehensive bactericidal activity of an ethanol-based hand gel in 15 seconds. Ann Clin Microbiol Antimicrob 2008;7:2.

11. Asaithambi A, Priyanka N, Snehalaxmi R, Uma A. Health-care associated infections and infection control practices in intensive care unit of a tertiary care hospital. Asian J Pharm Clin Res 2016;9:399-402.

12. David O, Olatunji F, Alese M, Babalola T, Alese O. Antimicrobial activity, safety and acceptability of formulated ginger-fortified hand sanitizer gel. Int J Trop Dis Heal 2017;2:1-11.

13. Alvarado D, Garcia J, Arias M. Evaluation of the effectiveness of alcohol-gel in the disinfection of hands and weakness over time. Biomedica 2010;1:29-31.

14. Mita S, Kusuma S, Insiyah N. Potent antibacterial of gel kawang fruits (Litocarpuscelebicus, (miq) rehder) ethanol extract origin from papua indonesia. Asian J Pharm Clin Res 2017;10:122-7.

15. Lavilla L, Benomar N, Galvez A, Abriouel H. Prevalence of bacteria resistant to antibiotics and/or biocides on meat processing plant surfaces throughout meat chain production. Int J Food Microbiol 2013;161:97-106.

16. Khatoon A, Arzoo A, Mohapatra A, Bihari K. Studies on in vitro evaluation of antibacterial activities of Eucalyptus Globuluslabill leaf. Int J Curr Pharm Res 2017;9:140-2. 